ARTICLE

\title{
Non-thermal plasma-assisted rapid hydrogenolysis of polystyrene to high yield ethylene
}

Libo Yao (1) ${ }^{1}$, Jaelynne King ${ }^{2}$, Dezhen $\mathrm{Wu}^{1}$, Jiayang $\mathrm{Ma}^{2}$, Jialu $\mathrm{Li}^{1}$, Rongxuan $\mathrm{Xie}^{1}$, Steven S. C. Chuang ${ }^{2}$, Toshikazu Miyoshi $\&$ Zhenmeng Peng (i) ${ }^{1 凶}$

The evergrowing plastic production and the caused concerns of plastic waste accumulation have stimulated the need for waste plastic chemical recycling/valorization. Current methods suffer from harsh reaction conditions and long reaction time. Herein we demonstrate a nonthermal plasma-assisted method for rapid hydrogenolysis of polystyrene (PS) at ambient temperature and atmospheric pressure, generating high yield (>40 wt\%) of $\mathrm{C}_{1}-\mathrm{C}_{3}$ hydrocarbons and ethylene being the dominant gas product (Selectivity of ethylene, $\mathrm{S}_{\mathrm{C} 2 \mathrm{H} 4}>70 \%$ ) within $\sim 10 \mathrm{~min}$. The fast reaction kinetics is attributed to highly active hydrogen plasma, which can effectively break bonds in polymer and initiate hydrogenolysis under mild condition. Efficient hydrogenolysis of post-consumer PS materials using this method is also demonstrated, suggesting a promising approach for fast retrieval of small molecular hydrocarbon modules from plastic materials as well as a good capability to process waste plastics in complicated conditions.

\footnotetext{
${ }^{1}$ Department of Chemical, Biomolecular and Corrosion Engineering, The University of Akron, 200 E Buchtel Avenue, Akron, OH 44325, USA. ${ }^{2}$ School of Polymer Science and Polymer Engineering, The University of Akron, 170 University Avenue, Akron, OH 44325, USA. 凶email: zpeng@uarkon.edu
} 
Fiveris or over a half century the fast development of plastic industry has been contributing greatly to the prosperity of human society. The global production of plastics has reached 400 million tons in 2018 and is still quickly growing, with the annual production being projected to double within two decades ${ }^{1}$. Accompanied by the big demand for plastic products, more and more plastic wastes (PWs) have been generated. It is reported that more than 300 million tons of PWs were generated in 2015 alone $^{2}$. As of date only less than $20 \%$ of these PWs can be recycled, with the rest ending up in landfills and incineration or being directly released to environment ${ }^{3}$

Mechanical process, which incorporates shredding, heating, and remolding of plastics, remained as the primary recycle method ${ }^{3}$. Despite the attraction for "closed-loop cycles", this method mainly produces "downgraded" plastics which have inferior properties" 4 . As a result, the number of reprocessing cycles is limited. Chemical processes including pyrolysis and gasification have been actively investigated for converting PWs to relatively low value-added synthesis gas and carbonaceous materials ${ }^{6-8}$. However, a high operating temperature $(700-1300 \mathrm{~K})$ is typically required to overcome the unfavorable thermodynamics and kinetics that makes these methods cost inhibitive. More recently, there have been a few studies on plastics hydrogenolysis. However, harsh reaction conditions of high temperature $(600-700 \mathrm{~K})$ and pressure (10-30 bar) and relatively long reaction time $(>6 \mathrm{~h})$ were still needed, suggesting low hydrogenolysis kinetics ${ }^{9-11}$.

Polystyrene (PS) has been widely used as food packages and foams and is among the top five most-produced plastic materials, other than polyethylene (PE), polypropylene (PP), polyethylene terephthalate (PET), and polyvinyl chloride (PVC), accounting for about $10 \%$ of global production ${ }^{12}$. Despite some active research efforts $^{13-15}$, few successes have been achieved in recycling this plastic material. As a matter of fact, only $1 \%$ of PS waste was recovered in US in $2015^{12}$. This comes from complex situations for separation (blended products and abundant sources of contaminants) and sorting (diversified density range $0.02-1.1 \mathrm{~g} / \mathrm{cm}^{3}$ ) of PS wastes that restrain their collection and the inability to process wastes under aforementioned complicated conditions. To overcome these practical challenges and claim better energy advantage, a method with the versatility to effectively depolymerize PS material under mild reaction conditions is needed.

Herein, we report a non-thermal plasma-enabled method which allows efficient hydrogenolysis of pure and post-consumer PS under ambient temperature and atmospheric pressure condition. Non-thermal $\mathrm{H}_{2}$ plasma provides a unique medium for generating reactive hydrogen species, primarily in form of ions and radicals, which can effectively break the $\mathrm{C}-\mathrm{C}$ bond in the polymeric structures and drive kinetically unfavorable reactions under mild reaction conditions ${ }^{16,17}$. In plastic pyrolysis, DBD plasma was also implemented to alter product selectivity ${ }^{18-20}$, but the process is still subject to high temperature $(>773 \mathrm{~K})$ together with extra power input which makes it less energetically attractive. This method achieves fast depolymerization of PS and generates $\mathrm{C}_{1}-\mathrm{C}_{3}$ hydrocarbons as major gas products. Interestingly, ethylene, an important precursor in the polymer industry, can be produced at a yield as high as $38 \mathrm{wt} \%$. Moreover, this nonthermal plasma-assisted hydrogenolysis method allows direct valorization of post-consumer PS products without a need for pretreatments and shows minimal influences by the contaminants and impurities. These findings reveal a great promise of this method for PWs valorization application.

\section{Results}

Time-dependent plasma-assisted PS hydrogenolysis. The nonthermal plasma-assisted PS hydrogenolysis experiments were conducted in a continuous flow fixed-bed reactor equipped with a dielectric barrier discharge (DBD) plasma generator ("Methods", Supplementary Fig. 1). The reaction results in the generation of gas, liquid, and solid products (Fig. 1a), which adds up to over $93 \mathrm{wt} \%$ of the total mass recovered (Supplementary Note 1 and Supplementary Tables 1,2), with a few percent of mass loss during the collection of liquid and solid products. Timedependent product distribution (denoted as PS-reaction time) shows a continuous increase in the gas products yield $\left(Y_{\mathrm{g}}\right)$ with reaction time, which reaches as high as $41.0 \mathrm{wt} \%$ after $12 \mathrm{~min}$ of reaction. Meanwhile, the solid phase keeps deminishing until to a minimal amount and the liquid products are obtained at a yield $\left(Y_{1}\right)$ ranging from $50 \mathrm{wt} \%$ to $56 \mathrm{wt} \%$ throughout the experiment. More than $95 \%$ of PS is converted to gas and liquid products within $12 \mathrm{~min}$ of reaction (Fig. 1a), indicating a fast hydrogenolysis rate. Online GC-MS analyses of the gas effluents find $\mathrm{C}_{1}-\mathrm{C}_{3}$ hydrocarbons as the major gas products (Fig. 1b). Except at the beginning of the reaction when methane is the dominant gas product with $53.2 \mathrm{wt} \%$ selectivity at $t=2 \mathrm{~min}$, ethylene is found as the primary gas product after a longer reaction time. The ethylene selectivity $\left(S_{\mathrm{C} 2 \mathrm{H} 4}\right)$ can reach as high as $>70 \%$, equivalent to $38 \mathrm{wt} \%$ yield among all products (PS-12min). This result confirms the efficient conversion of PS to gaseous hydrocarbons, especially the more valuable ethylene, via plasma-assisted hydrogenolysis.

The liquid products were collected using $\mathrm{CHCl}_{3}$ extractant from the resultant liquid-solid mixture after reaction. ${ }^{1} \mathrm{H}$ NMR spectra of the obtained liquid products indicate the transformation of polystyrene to styrene-based monomers and oligomers which is evidenced by the emergence of sharp, dense peaks in response to aromatic rings $(8-6 \mathrm{ppm})$, vinyl groups $(6-5 \mathrm{ppm})$ and $\mathrm{H}_{\alpha}$ with respect to aromatic functional groups (3-2 ppm), suggesting the significant extent of depolymerization in the liquid components (Fig. 1c) ${ }^{21}$. The monomer and oligomer formation is further confirmed by ${ }^{13} \mathrm{C}$ NMR spectroscopy (Supplementary Fig. 4) ${ }^{22}$. GPC was employed to characterize $\mathrm{Mw}$ of the liquid product components (Fig. 1d). The Mw profiles of all examined samples exhibit a multi-modal distribution (1-3 modes) owing to the feature of PS feedstock ${ }^{23}$. Two Mw modes, with one at $119,000 \mathrm{Da}$ and the other at $1700 \mathrm{Da}$, were observed for pure PS (Table 1), amounting to $\sim 35,000 \mathrm{Da}$ average molecular weight. From PS-0min to PS-12min, the hydrogenolysis reaction reduces the high Mw mode by a factor of 10 and the weight percentage of the lower Mw mode also exhibits a significant decrease. Meanwhile, a mode with a much lower Mw of about $300 \mathrm{Da}$ emerges intensively, indicating fast depolymerization of PS within a short reaction time. Characterizations of the solid residues using FT-IR and high-resolution solid-state ${ }^{13} \mathrm{C}$ NMR suggest the remaining solids are primarily PS with no detection of other species (Supplementary Figs. 5, 6, Supplementary Table 3).

Detailed structural and compositional information of the liquid products was obtained with Matrix-assisted Laser Desorption/ Ionization (MALDI-MS) and Electrospray Ionization (ESI-MS) techniques ("Methods", Supplementary Note 2). The former one was used to characterize large polymer units $(>800 \mathrm{Da})$, and the latter was used to characterize the low $\mathrm{Mw}$ range molecules $(0-800 \mathrm{Da})^{24}$. MALDI-MS detects a series of styrene oligomers with 5-45 monomer units (500-5000 Da) consisting of cyclic (red) and linear (blue) structures with $16 \mathrm{Da} \mathrm{Mw}$ difference (Fig. 2a, b, Supplementary Fig. 7), depending on whether end groups $\left(-\mathrm{CH}_{3}\right.$ on one end, $-\mathrm{H}$ on the other) were available. A sharp increase in the fraction of 5-15 monomer units was observed with a longer reaction time (Supplementary Fig. 8), suggesting an accelerated degree of depolymerization. Four types of compound structures were identified from the ESI results, including linear hydrocarbons, PS, hydro-PS, and dehydro-PS 
(a)

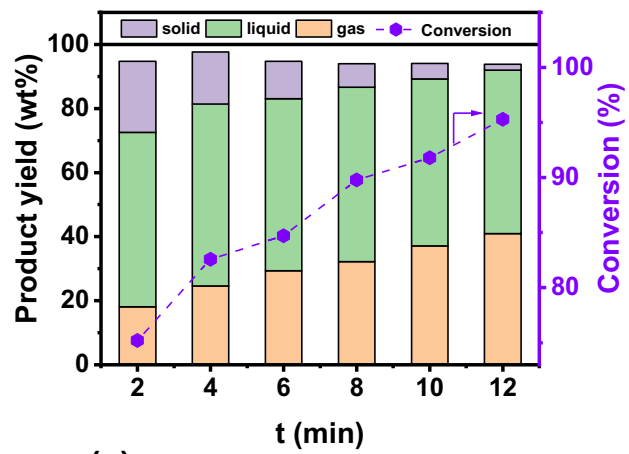

(b)

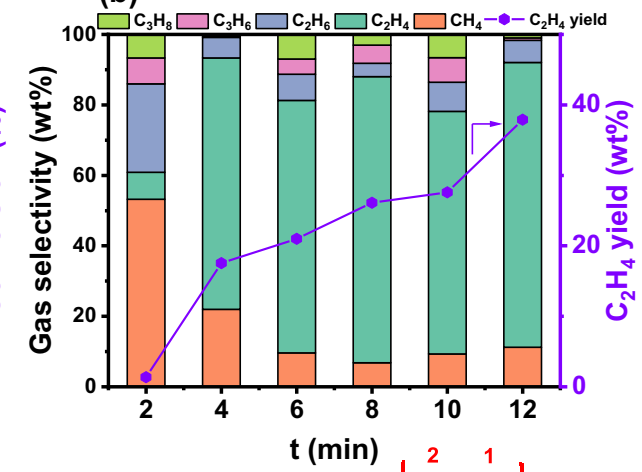

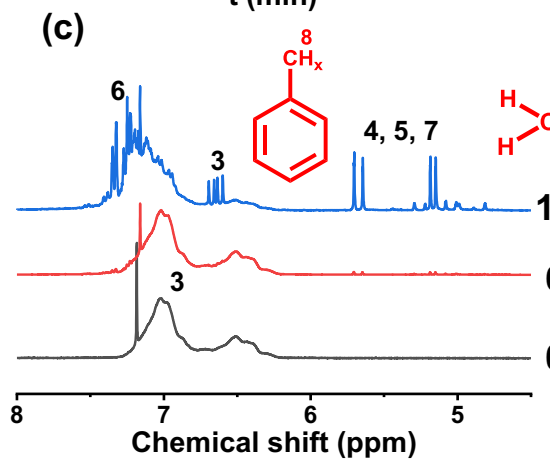

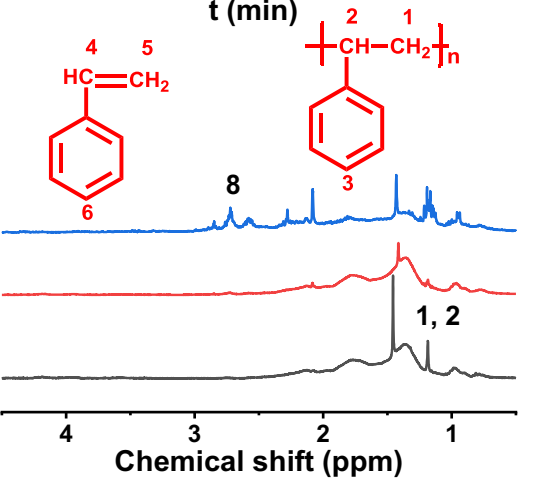

(d)

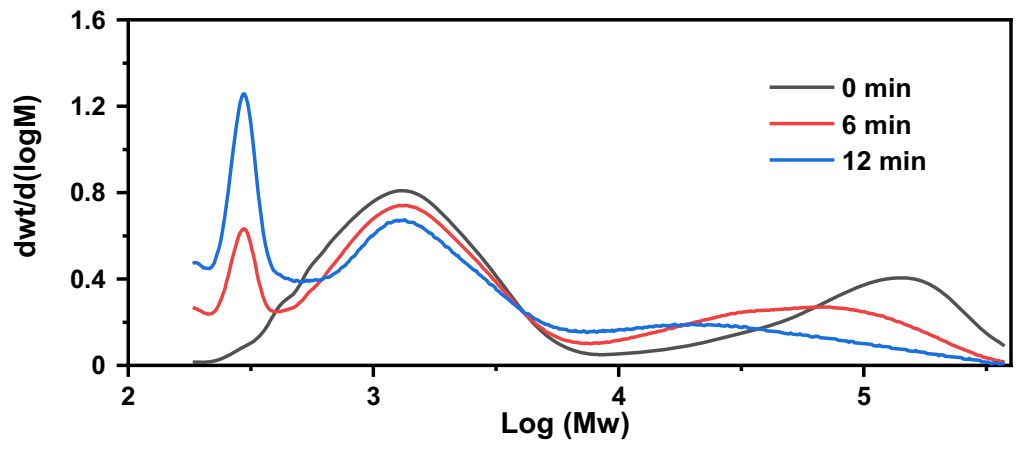

Fig. 1 Time-dependent reaction properties of plasma-assisted PS hydrogenolysis. a Product yield $(Y)$ and conversion ( $X$ ) and (b) gas product selectivity and ethylene yield as a function of reaction time $(t)$. c ${ }^{1} \mathrm{H}$ NMR spectra and (d) GPC spectra of liquid products after different reaction time (PS-Omin, PS$6 \mathrm{~min}$, and PS-12min). Reaction conditions: $\nu_{\mathrm{H} 2}=100 \mathrm{ml} / \mathrm{min}, P_{\mathrm{H} 2}=101 \mathrm{kPa}, P=90 \mathrm{~W}$.

\begin{tabular}{|c|c|c|c|c|c|c|c|}
\hline \multirow[t]{2}{*}{ Entry } & \multirow[t]{2}{*}{$t(\min )$} & \multirow[t]{2}{*}{ Conversion (\%) } & \multirow{2}{*}{\multicolumn{2}{|c|}{$\begin{array}{l}M w \\
\left(\times 10^{3} \mathrm{Da}\right)\end{array}$}} & \multicolumn{3}{|c|}{ Yield (wt\%) } \\
\hline & & & & & Gas & Liquid $^{[a]}$ & Solid \\
\hline 1 & 0 & - & 123 & 1.8 & - & - & - \\
\hline 2 & 2 & 75.21 & 119 & 1.7 & 18.07 & 54.52 & 22.17 \\
\hline 3 & 4 & 82.59 & 72 & 1.9 & 24.60 & 56.82 & 16.23 \\
\hline 4 & 6 & 84.72 & 69 & 1.8 & 29.32 & 53.75 & 11.64 \\
\hline 5 & 8 & 89.80 & 57 & 1.7 & 32.16 & 54.45 & 7.37 \\
\hline 6 & 10 & 91.80 & 37 & 1.8 & 37.13 & 52.11 & 4.81 \\
\hline 7 & 12 & 95.30 & 31 & 1.8 & 40.99 & 50.98 & 1.86 \\
\hline
\end{tabular}

oligomers (Supplementary Figs. 9-14, Fig. 2c). Their relative amounts as a function of reaction time were analyzed based on the ESI signals intensity (Supplementary Fig. 15), with the trends pointing to possible interconversion among these compounds through hydrogenation. With these characterization results, carbon number and ring distribution of the liquid products are summarized in Fig. 2d and Supplementary Fig. 16-21. A longer reaction time leads to the production of lighter and more narrowly distributed liquid products, with more $\mathrm{C}_{6}-\mathrm{C}_{9}$ chemicals in form of linear alkanes and alkylbenzenes being eventually produced after $12 \mathrm{~min}$ of hydrogenolysis reaction (Supplementary Fig. 22). Besides the reaction time, other reaction parameters, including $\mathrm{H}_{2}$ flow rate $\left(v_{\mathrm{H} 2}\right)$, partial pressure $\left(P_{\mathrm{H} 2}\right)$, mass of PS $\left(m_{\mathrm{PS}}\right)$ and power input $(P)$ were also examined and exhibited certain influences on the PS hydrogenolysis properties (Supplementary Note 3, Supplementary Figs. 23-27).

$D_{2}$ isotope labeling experiments and proposed reaction pathway. $\mathrm{D}_{2}$ isotope labeling experiments were conducted by replacing $\mathrm{H}_{2}$ with $\mathrm{D}_{2}$ to achieve insights into the plasma-assisted PS hydrogenolysis mechanism. It should be noted that the reaction pathway was proposed based on analyses of gas and liquid products, the potential influence of surface etching and irradiation and their impacts on PS decomposition was neglected due to fast kinetics of hydrogenolysis reaction. Figure $3 \mathrm{a}-\mathrm{d}$ shows the timeevolved MS spectra collected under the reaction condition. HD 


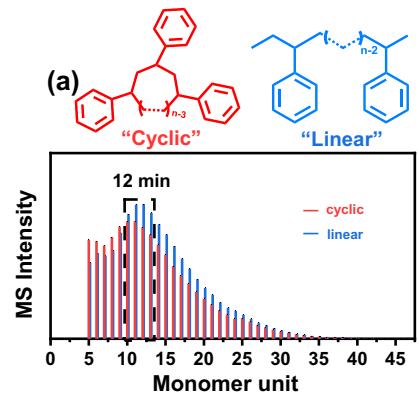

(c)

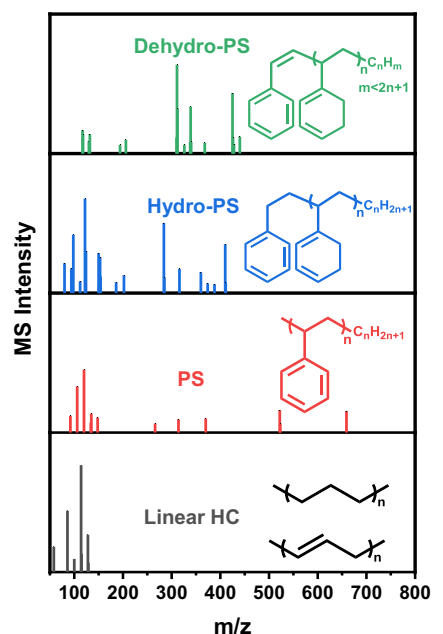

(d)

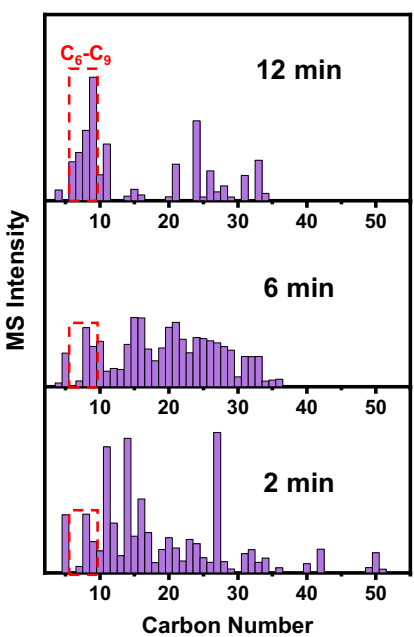

Fig. 2 MS characterization of PS hydrogenolysis liquid products. a MALDI-MS spectrum of PS-12min with Mw ranging from 500 to 5000 Da. Cyclic and linear polystyrenes were represented in red and blue, respectively. b Zoom-in of MALDI spectrum from (a), between 9 and 15 monomer units. c Structural classification of compounds on the ESI-MS spectra for PS-12min as a function of ion mass/charge number (m/z). Linear hydrocarbon (Linear HC, black), polystyrene (PS, red), hydrogenated polystyrene (Hydro-PS, blue), and dehydrogenated polystyrene (Dehydro-PS, green) were identified and represented. d Comparison of carbon number distribution among PS-2min, PS-6min, and PS-12min.

(a)

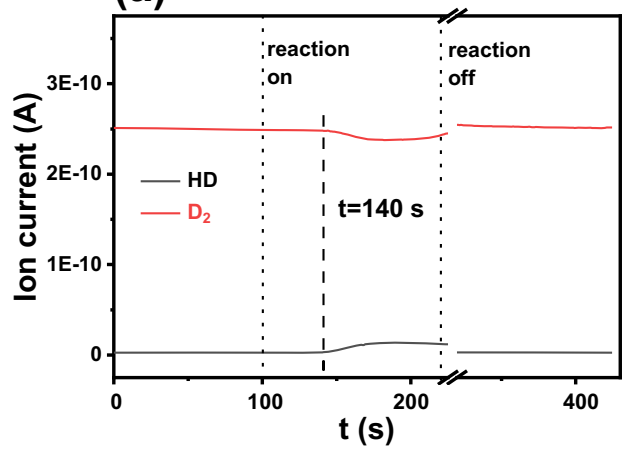

(c)

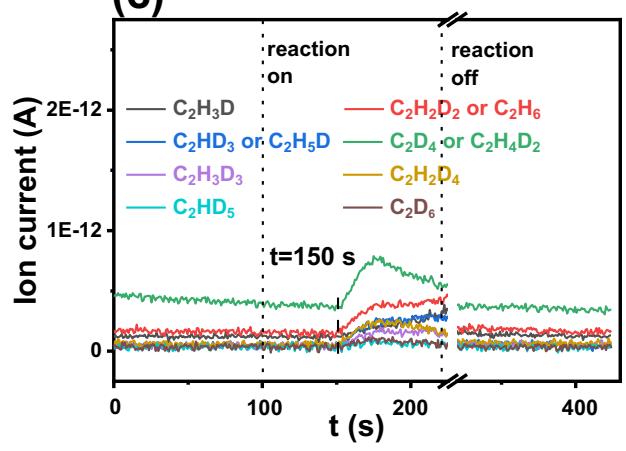

(b)

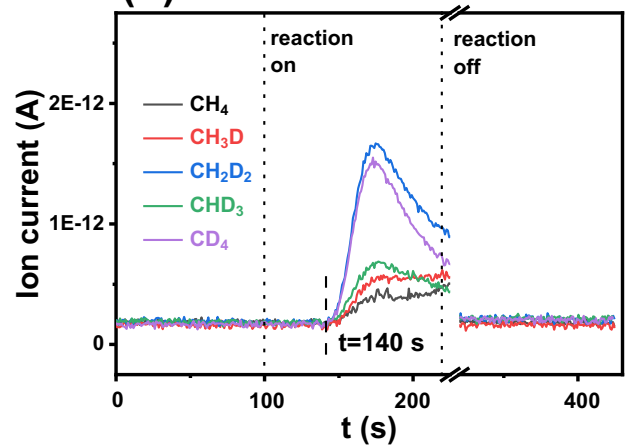

(d)

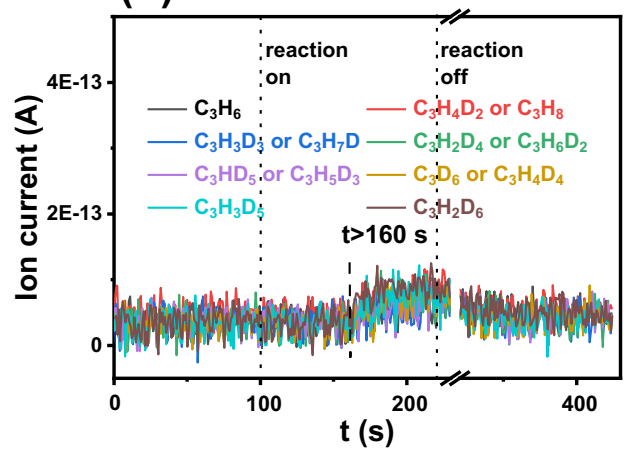

Fig. 3 Time-evolved $(\boldsymbol{t})$ gas products evolution during $\mathbf{D}_{\mathbf{2}}$ isotope labeling PS hydrogenolysis reaction. Mass spectra for (a) $H_{2}(H D),(\mathbf{b}) C_{1},(\mathbf{c}) C_{2}$, and (d) $C_{3}$ species. The reaction was switched on at $100 \mathrm{~s}$, and switched off after $120 \mathrm{~s}$.

signals are detected starting from about $40 \mathrm{~s}$ after the reaction is switched on (Fig. 3a). Considering only PS contains hydrogen, the generation of HD should be resultant of reaction between highly active deuterium plasma species and PS, which generates hydrocarbon fragments and hydrogen species that would further react with deuterium. Interestingly, the generation of various hydrocarbon gas products exhibits a different reaction time dependence. Methane and deuterium-exchanged methane products begin to be detected simultaneously with $\mathrm{HD}$ generation (Fig. 3b), with $\mathrm{CH}_{2} \mathrm{D}_{2}$ and $\mathrm{CD}_{4}$ being the major products. In comparison, there are about 10 more seconds of delay for $\mathrm{C}_{2}$ products detection and about 20 more seconds of delay for $\mathrm{C}_{3}$ products detection (Fig. 3c, d). These results suggest the formation of gas products following an order of $\mathrm{CH}_{4}>\mathrm{C}_{2} \mathrm{H}_{4} \approx \mathrm{C}_{2} \mathrm{H}_{6}>$ 


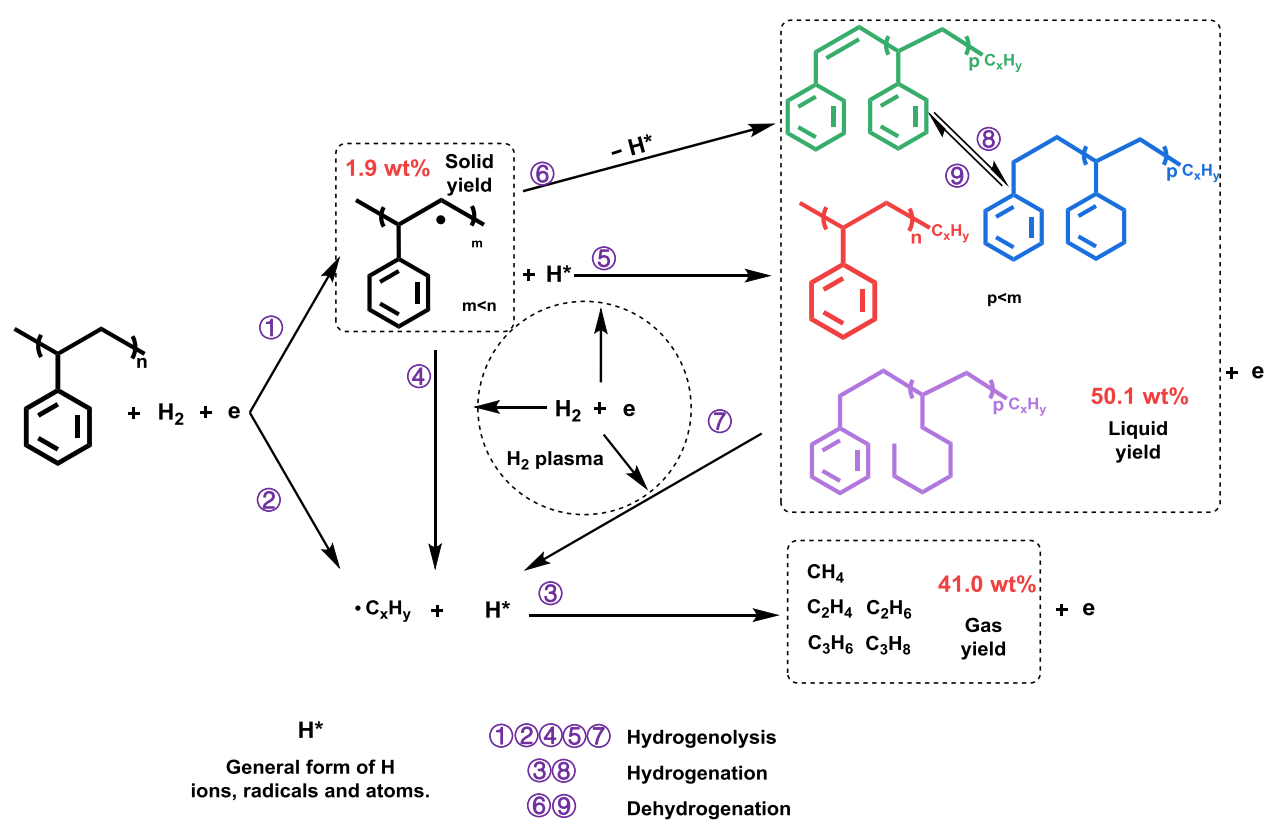

Fig. 4 Illustrated reaction pathways for plasma-assisted PS hydrogenolysis. Product yield information shown in the figure is for PS-12min.

$\mathrm{C}_{3} \mathrm{H}_{6} \approx \mathrm{C}_{3} \mathrm{H}_{8}$ at the initiation of the PS hydrogenolysis. They should be primarily generated via a combination between plasmaactivated $\mathrm{H}$ species resultant of $\mathrm{H}_{2}$ dissociation and ${ }^{-} \mathrm{C}_{x} \mathrm{H}_{y}$ species resultant of PS fragmentation, either from the PS aliphatic chains or the opened aromatic structures. Based on the collective information of gas and liquid products, a plausible reaction network for the plasma-assisted PS hydrogenolysis is illustrated in Fig. 4. Interacted with $\mathrm{H}_{2}$ plasma, $\mathrm{C}-\mathrm{H}$ and $\mathrm{C}-\mathrm{C}$ bonds in $\mathrm{PS}$ can be effectively broken, resulting in hydrocarbon fragments including smaller units of PS (step 1) and ${ }^{-} \mathrm{C}_{x} \mathrm{H}_{y}$ species (step 2). The latter would serve as precursors for gas products by means of subsequent hydrogenation (step 3). The former would either be further fragmentized by $\mathrm{H}_{2}$ plasma to generate more $\cdot \mathrm{C}_{x} \mathrm{H}_{y}$ radicals (step 4) and/or form liquid products (PS, hydro-PS) through hydrogenolysis (step 5). Besides, a dehydrogenation pathway to form dehydro-PS would also be likely (step 6), as revealed by the formation of dehydro-PS liquid product (Supplementary Fig. 19) and the HD formation in the isotope labeling experiments (Fig. 3a). Interconversion among liquid products (steps 8 and 9) would occur as well, as evidenced from the timedependent MS signals (Supplementary Fig. 15).

Thermodynamic analyses. Thermodynamics of the overall PS hydrogenolysis process was assessed using the Benson group additivity method (Supplementary Note 4, Supplementary Fig. 28 and Supplementary Table 7$)^{25}$. The thermodynamic contributions of individual reactions under the standard condition were calculated and tabulated in Supplementary Table 8. Both depolymerization and gas formation facilitated by plasma-assisted hydrogenolysis, i.e., the major reactions being observed in the experiments, show negative $\Delta G$ values (Supplementary Table 8), suggesting favorable thermodynamics for the overall reaction under standard condition. All the calculated reactions are exothermic except for the formation of $\mathrm{C}_{2} \mathrm{H}_{4}$ and $\mathrm{C}_{3} \mathrm{H}_{6}$ (Supplementary Table 8). The reactor temperature after $12 \mathrm{~min}$ of reaction is measured to be about $200{ }^{\circ} \mathrm{C}$ (Supplementary Table 9), which should be resultant of accumulated plasma heat effect and would benefit endothermic $\mathrm{C}_{2} \mathrm{H}_{4}$ formation ${ }^{26,27}$, leading to improvement in kinetics and yields shown in Fig. 1b. Moreover, the net enthalpy that incorporates molar contributions of gas formation reactions
(Supplementary Fig. 29) switches the reaction thermodynamics after $2 \mathrm{~min}$ of reaction (Supplementary Table 10). The calculated thermodynamic properties, backed up by the measured reaction performance, provide a basis to understand the PS hydrogenolysis process, especially for the formation of gas products.

Post-consumer PS (PCPS) hydrogenolysis. Our study on postconsumer PS (PCPS) materials proves a good capability of this plasma-assisted hydrogenolysis method to effectively convert PS wastes into valuable chemicals. Commercially available yogurt containers (Supplementary Fig. 30), an important application for PS, were used as feedstock. Identical reaction conditions were applied for PCPS as for pure PS. An $85.2 \mathrm{wt} \%$ conversion is achieved after 12 min of reaction (Fig. 5a), which is about $10 \%$ lower than that for PS. The existence of unconvertable impurities, such as contaminants, dyes and reinforcement materials, etc., is likely responsible for the conversion reduction by increasing the weight percentage of solid and uncollected substances (Supplementary Tables 11, 12). As high as $41 \mathrm{wt} \%$ gas yield is obtained at PCPS-12min, with ethylene still being the dominant gaseous product (71 wt $\%$ selectivity and $34 \mathrm{wt} \%$ yield, Fig. $5 \mathrm{~b}$ ). The liquid products show a decrease in both yield and average molecular weight as a function of time (Fig. $5 a, c$, and d). Almost one order of magnitude reduction in the $\mathrm{Mw}$ is observed from PCPS-4min to PCPS-12min, based on which a high degree of PS depolymerization from the feedstock can be concluded. This was further confirmed by the MALDI-MS spectra (Fig. 5e). Like the experiments for pure PS, the ESI-MS results exhibit resemblance in the structures of components (Supplementary Figs. 31-34). The carbon number distribution also indicates an enrichment of $\mathrm{C}_{6}-\mathrm{C}_{9}$ chemicals, and a reduction of heavier components with reaction time (Supplementary Fig. 35). Furthermore, the capability of processing various substrates such as polyethylene (PE) and polypropylene (PP), as well as mixtures of the three substrates (3P) was demonstrated (Supplementary Fig. 36). Even higher gas yield was obtained by PE (51.7\%), PP (68.5\%), and 3P (50.55\%) compared with PS, with a dominant gas product varying from plastic monomers. These results suggest the capability of this method in processing real-world plastic wastes which typically consist of mixtures of various polymers. 
(a)

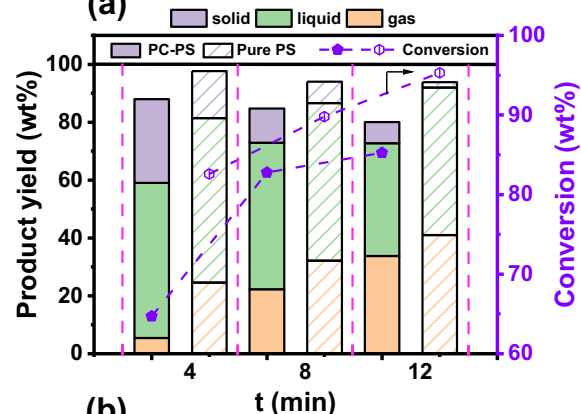

(b)

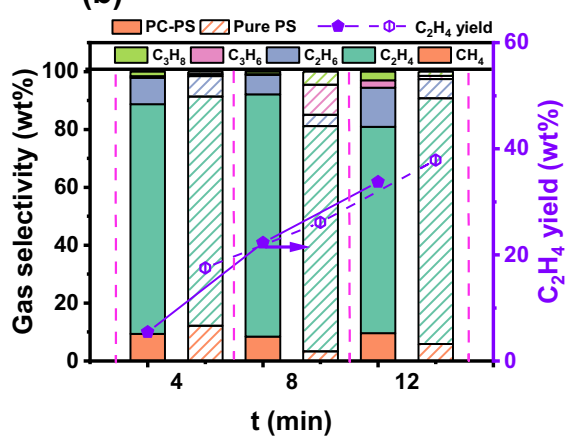

(c)
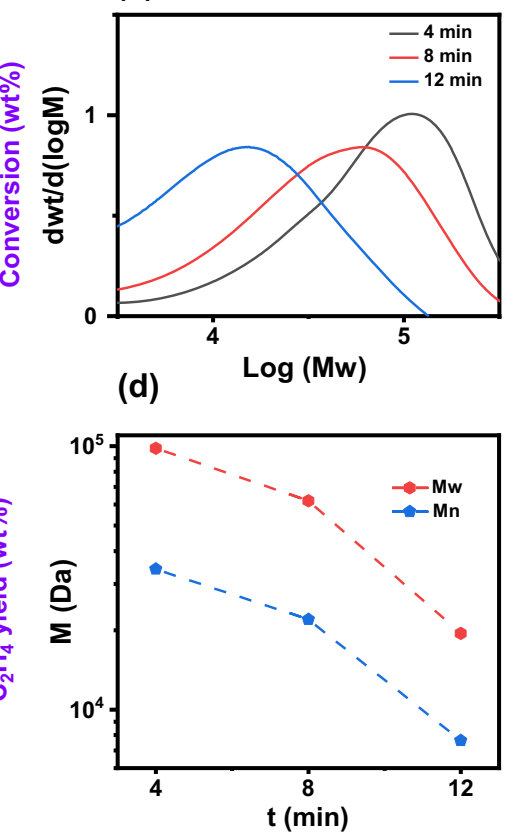

(e)

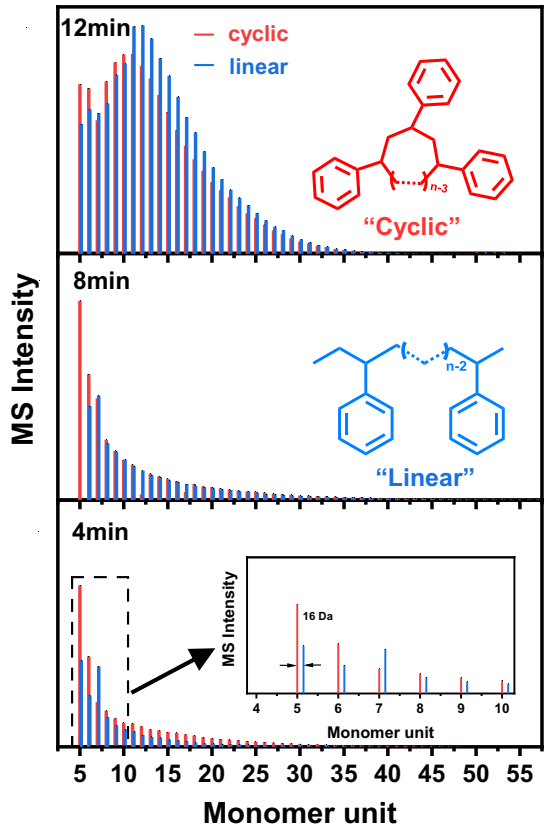

Fig. 5 Plasma-assisted post-consumer PS (PCPS) hydrogenolysis properties as a function of reaction time. a Product yield and conversion properties. b Gas products selectivity and ethylene yield properties. c, d GPC spectra and molecular weight evolution as a function of reaction time. e MALDI-MS spectra of liquid components obtained from PCPS-4min, PCPS-8min and PCPS-12min, respectively. Cyclic and linear polystyrenes were represented in red and blue, respectively.

\section{Discussion}

In summary, our study demonstrates a method for rapid polystyrene hydrogenolysis to light hydrocarbons. Enabled by $\mathrm{H}_{2}$ nonthermal plasma, over $90 \mathrm{wt} \%$ PS can be swiftly depolymerized and converted to $\mathrm{C}_{1}-\mathrm{C}_{3}$ hydrocarbons and liquid products within $12 \mathrm{~min}$ of reaction. The valuable ethylene gas is the most dominating product, accounting for as high as $38 \mathrm{wt} \%$ of total yield. Enriched $\mathrm{C}_{6}-\mathrm{C}_{9}$ paraffins and alkylbenzenes that possess high commercial values are obtained in the liquid products. Furthermore, investigation on post-consumer PS materials exhibits similarly efficient gas production regardless of the existence of contaminants and additives. Our studied method for PS hydrogenolysis not only achieves fast and efficient transformation to valuable gas products, but also shows the capability of processing waste plastics with complicated forms and conditions, which is one of the most challenging issues for plastic valorization.

Despite these advantageous features revealing a good potential of this method for real application that helps to realize recycling of currently untouched plastic waste materials, some issues need to be considered before taking on a larger scale. The most challenging problem, not only for the plastic processing but for any other better developed NTP-assisted reactions such as $\mathrm{CO}_{2}$ conversion, VOC removal, and $\mathrm{N}_{2}$ fixation is the energy efficiency ${ }^{28,29}$. The mismatch between the power input and output (represented by the amount of product) restrains further application of this technique. The time-dependent energy efficiency $(\eta, g / k W h)$ of gas production is calculated and shown in Supplementary Fig. 3. Methane and ethylene demonstrated the highest energy efficiency between 6 and $7 \mathrm{~g} / \mathrm{kWh}$ within $4 \mathrm{~min}$ of the reaction, and gradually decreases with a longer reaction time. Comparing with other well-established DBD plasma-assisted reactions such as $\mathrm{CO}_{2}$ conversion, VOC abatement and $\mathrm{N}_{2}$ fixation (Supplementary Fig. 3b), the optimal energy efficiency values obtained from gas products only in the plastic hydrogenolysis exhibit comparable or even superior energy efficiency ${ }^{30,31}$. Considering the unaccounted liquid products, the energy efficiency can be even higher. For future perspective, we propose there are three strategies that can be applied to further improve the energy efficiency. First, elegantly designing DBD plasma generator, reactor, as well as plastic packing methods could help mitigate the power lost to non-plasma zone and unavoidable heat. Second, screening appropriate catalyst, which has been proved in our previous study ${ }^{16}$. Third, as the timedependent energy efficiency shown in Supplementary Fig. 3a suggests the highest energy efficiency was achieved within the first 2-4 min, which then gradually decreased with a longer reaction time. It is suggested that pulsed or segmental instead of continuous plasma to be applied so that the reaction could remain high EE.

An ideal industrial plastic chemical recycling/upcycling method should be able to process waste plastics swiftly, efficiently, and continuously. Currently, the rapidly growing research efforts in plastic hydrogenolysis mainly focus on depolymerizing various plastics in batch reactors, with pressurized $\mathrm{H}_{2}$ atmosphere (20-60 bar), high temperature $\left(200-300^{\circ} \mathrm{C}\right.$ ) and long reaction time $(1-40 \mathrm{~h})$ being applied (Supplementary Table 13). Our presented method outperforms the state-of-art studies in the promise for scaling up with fast, selective, and continuous gas production.

\section{Methods}

Materials and gases. Polystyrene (PS, Sigma Aldrich, average Mw 35000, Stock No. 331651). Chloroform-D (99.8\%, Cambridge Isotope Laboratories, Inc. Lot\# DLM-7-PK), $\mathrm{CHCl}_{3}$ (>99.8\%, Sigma Aldrich, Lot\# 132950). $\mathrm{H}_{2}$ (99.999\%), $\mathrm{D}_{2}$ (99.999\%) and $\operatorname{Ar}(99.999 \%)$ gases were purchased from Praxair. Calibration gas for $1 \%$ methane $\left(\mathrm{CH}_{4}, 135 \mathrm{~N}-1 \%\right)$, acetylene $\left(\mathrm{C}_{2} \mathrm{H}_{2}, 17 \mathrm{~L}-\mathrm{m} 24-1 \%-\mathrm{CGD}\right)$, ethylene $\left(\mathrm{C}_{2} \mathrm{H}_{4}, 17 \mathrm{~L}-62 \mathrm{a}-1 \%\right)$, ethane $\left(\mathrm{C}_{2} \mathrm{H}_{6}, 17 \mathrm{~L}-\mathrm{m} 23-1 \%\right)$, propylene $\left(\mathrm{C}_{3} \mathrm{H}_{6}, 17 \mathrm{~L}-293 \mathrm{~N}-1\right)$ and propane $\left(\mathrm{C}_{3} \mathrm{H}_{8}, 17 \mathrm{~L}-175-1\right)$ were purchased from CAL GAS DIRECT ${ }^{\mathrm{TM}}$.

Plasma-assisted PS hydrogenolysis reaction. Non-thermal plasma-assisted PS hydrogenolysis experiments were conducted in a quartz tube reactor equipped with a dielectric barrier discharge (DBD) plasma generator, with cold hydrogen plasma being generated at the plasma generation zone (Supplementary Fig. 1). The volume of the plasma zone ( $\left.V_{\text {plasma }}\right)$ is approximately $6.28 \mathrm{~cm}^{3}$. In a typical run, $200 \mathrm{mg}$ PS pellets (sieved to the size of $125-250 \mu \mathrm{m}$ ) were packed in the DBD reactor. The standard reaction condition was $100 \mathrm{ml} / \mathrm{min}_{2}$ flow rate, $101 \mathrm{kPa} \mathrm{H}$ partial pressure and $90 \mathrm{~W}$ plasma power unless being stated otherwise. Influences of 
various reaction parameters, including reaction time (2-12 $\mathrm{min}), \mathrm{H}_{2}$ flow rate $(20-100 \mathrm{ml} / \mathrm{min}), \mathrm{H}_{2}$ partial pressure $(0-101 \mathrm{kPa})$, mass of reactant $(100-600 \mathrm{mg})$ were examined.

The mass of the gas, liquid, and solid products were mainly measured via weight reduction method. The gas product was quantified by measuring the weight loss of the packed reactor before and after the reaction. The liquid product was obtained from the extractant of $\mathrm{CHCl}_{3}$ from the liquid-solid mixture in the reactor, while the insoluble resultants were the solid residues (PS + quartz wool). The weight of the solid product was calculated by the difference between quartz wool and solid residues, and liquid product was calculated by the total weight of $\mathrm{CHCl}_{3}$ solution minus the weight of solvent. In Supplementary Table 1 a rigorous mass balance calculation is shown which indicates $1.2 \%$ error in terms of PS weight. All experiments exhibit $<5 \%$ error (Supplementary Table 2 ). The calculation of conversion $(X, \%)$ and yield $(Y, w t \%)$ is shown in the following equations, in which $m_{\mathrm{PS}}, m_{\mathrm{gas}}, m_{\text {liquid }}$ and $m_{\text {solid }}$ represent the mass of polystyrene, gas, liquid, and solid products, respectively. $m_{\mathrm{us}}$ represents the uncollected solid which is not taken into account any one of the product category:

$$
\begin{gathered}
\text { Conversion }(X)=\frac{m_{\mathrm{PS}}-m_{\text {solid }}-m_{\mathrm{us}}}{m_{\mathrm{PS}}} \times 100 \% \\
\text { Yield }(Y)=\frac{m_{\text {gas }} / m_{\text {liquid }} / m_{\text {solid }}}{m_{\mathrm{PS}}} m_{\text {solid }} \times 100 \%
\end{gathered}
$$

Product analysis and characterization. Online gas product analysis. The gas effluent products, including $\mathrm{CH}_{4}, \mathrm{C}_{2} \mathrm{H}_{2}, \mathrm{C}_{2} \mathrm{H}_{4}, \mathrm{C}_{3} \mathrm{H}_{6}$, and $\mathrm{C}_{3} \mathrm{H}_{8}$, were analyzed with an online Agilent $6890 \mathrm{GC}-\mathrm{MS}$ equipped with the automatic gas injector. The gases were quantified separately by externally feeding standard calibration gas. Calibration curves at $0-5 \% \mathrm{v} / \mathrm{v} \%$ were obtained for each gas. Selectivity was calculated by the respective gas production rate divided by the overall production rate $(\mathrm{g} / \mathrm{min})$.

NMR spectroscopy. Liquid products after plasma-assisted hydrogenolysis reaction were analyzed by ${ }^{1} \mathrm{H}-\mathrm{NMR}$ and ${ }^{13} \mathrm{C}-\mathrm{NMR}$, respectively. ${ }^{1} \mathrm{H}-\mathrm{NMR}$ experiments were conducted with a Varian Mercury $300 \mathrm{MHz}$ spectrometer. ${ }^{13} \mathrm{C}$-NMR spectra were recorded with Varian NMRS $500 \mathrm{MHz}$ spectrometer. Chemical shifts $(\delta, \mathrm{ppm})$ were calibrated using residual proton signals of the solvent and referenced to tetramethylsilane (TMS).

Matrix-assisted laser desorption/ionization mass spectroscopy (MALDI-MS). MALDI-MS analyses were conducted with a Bruker UltraflexIII MALDI-ToF/ToF instrument. A sandwich method for matrix and sample application was applied. First layer: $20 \mathrm{mg} / \mathrm{ml}$ trans-2-[3-(4-tert-Butylphenyl)-2-methyl-2-propenylidene] malononitrile (DCTB) matrix and $10 \mathrm{mg} / \mathrm{ml}$ silver trifluoroacetate (AgTFA) salt (10:1). Second layer: tested sample at a given concentration. Third layer: $20 \mathrm{mg} / \mathrm{ml}$ DCTB matrix and $10 \mathrm{mg} / \mathrm{ml}$ AgTFA salt (10:1). The analyses were performed in reflection and a linear mode. Detection range between 500 and 10,000 Da. Laser intensity was $40 \%$

Electrospray ionization mass spectroscopy (ESI-MS). The experiments were conducted using Waters Synapt G1 ESI-Q Time-of-flight (ToF) MS instrument. The desolvation temperature was $250^{\circ} \mathrm{C}$, the source temperature was $120^{\circ} \mathrm{C}$, the capillary voltage was $3.00 \mathrm{kV}$ and the flow rate was $10 \mu \mathrm{l} / \mathrm{min}$. Samples were diluted to $10 \mu \mathrm{g} / \mathrm{ml}$ in methanol.

Gel permeation chromatography (GPC). Analyses were performed on a Waters GPC system comprised of a Waters 1515 isocratic HPLC pump, using two $7.8 \times$ $300 \mathrm{~mm}$ Styragel HR 4E THF (waters WAT044240), with a Waters 2414 refractive index detector. The system was calibrated using 14 polystyrene standards ranging 201-411,000 Da. The injection volume was $100 \mathrm{uL}$ with a flow rate of $1.0 \mathrm{~mL} / \mathrm{min}$. Samples were diluted in THF in concentrations $1-10 \mathrm{mg} / \mathrm{ml}$. Data were processed using the Waters Breeze ${ }^{\mathrm{TM}}$ V3.30 software.

FT-IR spectroscopy. Solid residues (mixture of quartz wool and reacted polystyrene solids) obtained after reaction were characterized by ex situ Fouriertransform IR spectroscopy with Nicolet 6700 IR spectrometer in diffuse reflectance IR Fourier-transform spectroscopy (DRIFTS) mode under ambient condition. The spectra were recorded by collecting 32 scans with a resolution of $2 \mathrm{~cm}^{-1}$. No specific correction was applied.

${ }^{13} \mathrm{C}$ Solid-state NMR spectroscopy. ${ }^{13} \mathrm{C}$ solid-state NMR experiments on pure and reacted PS samples were conducted by a Bruker Avance Ultrashield 300 NMR apparatus equipped with a $4 \mathrm{~mm}$ double resonance VT CP/MAS probe. The ${ }^{13} \mathrm{C}$ and ${ }^{1} \mathrm{H}$ carrier frequencies were 75.6 and $300.1 \mathrm{MHz}$, respectively. Samples were packed in a $4 \mathrm{~mm}$ Zirconia MAS rotor with a Kel-F drive cap and were measured with a MAS speed of $13000 \pm 5 \mathrm{~Hz}$ at $25^{\circ} \mathrm{C} .{ }^{13} \mathrm{C}$ and ${ }^{1} \mathrm{H}$ rf filed strength was adjusted to 55.6 and $75 \mathrm{kHz}$, respectively. ${ }^{1} \mathrm{H}$ TPPM decoupling was used during acquisition. Cross polarization and recycle delay were set to $2 \mathrm{~ms}$ and $3 \mathrm{~s}$, respectively. ${ }^{13} \mathrm{C}$ chemical shift was externally referenced as the $\mathrm{CH}$ carbon of adamantane as $29.46 \mathrm{ppm}$.

$D_{2}$ isotope-labeled plasma-assisted PS hydrogenolysis reaction. The $\mathrm{D}_{2}$ exchanged PS hydrogenolysis reaction was conducted in the same tube reactor described in the previous context, connected with a Pfeiffer Omnistar GSD 320 MS instrument. In a typical run, $200 \mathrm{mg}$ PS was packed in the tube reactor, with $100 \mathrm{ml} / \mathrm{min} \mathrm{D}_{2}$ gas being continuously flowed through, plasma power was set at $90 \mathrm{~W}$ for a 2 min reaction.
Post-consumer PS hydrogenolysis. Post-consumer polystyrene plasma-assisted hydrogenolysis reaction was conducted using commercially available yogurt packages that are made of polystyrene blended with dyes and reinforcement materials. The post-consumer material was cut, shredded, and packed in the DBD reactor with a similar configuration to that of pure PS powder. The methods applied for reaction evaluation (i.e. yield calculation, product analysis, and reaction parameters) were identical to those conducted for pure PS material.

\section{Data availability}

The main data supporting the findings in this study are provided in the paper and Supplementary information. Additional data are available from the corresponding authors upon reasonable request.

Received: 22 June 2021; Accepted: 24 January 2022; Published online: 16 February 2022

\section{References}

1. Geyer, R., Jambeck, J. R. \& Law, K. L. Production, use, and fate of all plastics ever made. Sci. Adv. 3, e1700782 (2017).

2. Lebreton, L. \& Andrady, A. Future scenarios of global plastic waste generation and disposal. Palgrave Commun. 5, 1-11 (2019).

3. Britt, P. F. et al. Report of the Basic Energy Sciences Roundtable on Chemical Upcycling of Polymers (USDOE Office of Science (SC), 2019).

4. La Mantia, F. P. Polymer mechanical recycling: downcycling or upcycling? Prog. Rubber Plast. Recycl. Technol. 20, 11-24 (2004).

5. Ragaert, K., Delva, L. \& Van Geem, K. Mechanical and chemical recycling of solid plastic waste. Waste Manag. 69, 24-58 (2017).

6. Vollmer, I. et al. Beyond mechanical recycling: giving new life to plastic waste Angew. Chem. Int. Ed. 59, 15402-15423 (2020).

7. Zhang, F. et al. Polyethylene upcycling to long-chain alkylaromatics by tandem hydrogenolysis/aromatization. Science 370, 437-441 (2020).

8. Tennakoon, A. et al. Catalytic upcycling of high-density polyethylene via a processive mechanism. Nat. Catal. 3, 893-901 (2020).

9. Rorrer, J. E., Beckham, G. T. \& Román-Leshkov, Y. Conversion of polyolefin waste to liquid alkanes with Ru-based catalysts under mild conditions. JACS Au 1, 8-12 (2020).

10. Nakaji, Y. et al. Low-temperature catalytic upgrading of waste polyolefinic plastics into liquid fuels and waxes. Appl. Catal. B: Environ. 285, 119805 (2021)

11. Sánchez-Rivera, K. L. et al. Catalytic hydrogenolysis of polyolefins into alkanes. ACS Cent. Sci. 7, 17-19 (2021)

12. Rahimi, A. et al. Steering chemical reactions with force. Nat. Rev. Chem. 1, 1-11 (2017)

13. Ukei, H. et al. Catalytic degradation of polystyrene into styrene and a design of recyclable polystyrene with dispersed catalysts. Catal. Today 62, 67-75 (2000).

14. Zhang, Z. et al. Chemical recycling of waste polystyrene into styrene over solid acids and bases. Ind. Eng. Chem. Res. 34, 4514-4519 (1995).

15. Maharana, T., Negi, Y. \& Mohanty, B. Recycling of polystyrene. Polym. Plast Technol. Eng. 46, 729-736 (2007).

16. Yao, L., King, J., Wu, D., Chuang, S. S. C. \& Peng, Z. Non-thermal plasmaassisted hydrogenolysis of polyethylene to light hydrocarbons. Catal. Commun. 150, 106274 (2021)

17. Neyts, E. C., Ostrikov, K., Sunkara, M. K. \& Bogaerts, A. Plasma catalysis: synergistic effects at the nanoscale. Chem. Rev. 115, 13408-13446 (2015).

18. Song, J. et al. Dielectric barrier discharge plasma synergistic catalytic pyrolysis of waste polyethylene into aromatics-enriched oil. ACS Sustain. Chem. Eng. 9 11448-11457 (2021)

19. Diaz-Silvarrey, L. S., Zhang, K. \& Phan, A. N. Monomer recovery through advanced pyrolysis of waste high density polyethylene (HDPE). Green. Chem. 20, 1813-1823 (2018).

20. Aminu, I., Nahil, M. A. \& Williams, P. T. Hydrogen from waste plastics by two-stage pyrolysis/low-temperature plasma catalytic processing. Energy Fuels 34, 11679-11689 (2020)

21. Bovey, F., Hood, F. III, Anderson, E. \& Snyder, L. Polymer NMR spectroscopy XI. Polystyrene and polystyrene model compounds. J. Chem. Phys. 42, 3900-3910 (1965)

22. Guo, N., Li, L. \& Marks, T. J. Bimetallic catalysis for styrene homopolymerization and ethylene-styrene copolymerization. Exceptional comonomer selectivity and insertion regiochemistry. J. Am. Chem. Soc. 126, 6542-6543 (2004)

23. Kim, Y. et al. New Half-metallocene catalysts generating polyethylene with bimodal molecular weight distribution and syndiotactic polystyrene. Macromol. Rapid Commun. 22, 573-578 (2001)

24. Murgasova, R. \& Hercules, D. M. Polymer characterization by combining liquid chromatography with MALDI and ESI mass spectrometry. Anal. Bioanal. Chem. 373, 481-489 (2002). 
25. Benson, S. W. et al. Additivity rules for the estimation of thermochemical properties. Chem. Rev. 69, 279-324 (1969).

26. Rodrigues, F., Pascoa, J. \& Trancossi, M. Heat generation mechanisms of DBD plasma actuators. Exp. Therm. Fluid Sci. 90, 55-65 (2018).

27. Wang, J. et al. One-step plasma-enabled catalytic carbon dioxide hydrogenation to higher hydrocarbons: significance of catalyst-bed configuration. Green. Chem. 23, 1642-1647 (2021).

28. Van Laer, K. \& Bogaerts, A. Improving the conversion and energy efficiency of carbon dioxide splitting in a zirconia-packed dielectric barrier discharge reactor. Energy Technol. 3, 1038-1044 (2015).

29. Wang, L., Yi, Y., Guo, H. \& Tu, X. Atmospheric pressure and room temperature synthesis of methanol through plasma-catalytic hydrogenation of $\mathrm{CO}_{2}$. ACS Catal. 8, 90-100 (2018).

30. Winter, L. R. \& Chen, J. G. $N_{2}$ Fixation by Plasma-activated Processes (Joule, 2020).

31. Wu, Z. et al. Enhanced energy efficiency and reduced nanoparticle emission on plasma catalytic oxidation of toluene using $\mathrm{Au} / \gamma-\mathrm{Al}_{2} \mathrm{O}_{3}$ nanocatalyst. Chem. Eng. J. 427, 130983 (2022).

\section{Acknowledgements}

The financial support of this work by the National Science Foundation (2132178) (S.C. T.M., and Z.P.) is acknowledged. We acknowledge Kayla Williams-Pavlantos for the help of MALDI- and ESI-MS analyses. We also appreciate the help from Peter Kosgei for GPC experiments.

\section{Author contributions}

L.Y., Z.P., S.C. and T.M. conceived the project and designed experiments; L.Y., J.K. D.W., J.M., J.L. and R.X. performed all the experiments; L.Y. wrote the manuscript with edits from all authors.

\section{Competing interests}

The authors declare no competing interests.

\section{Additional information}

Supplementary information The online version contains supplementary material available at https://doi.org/10.1038/s41467-022-28563-7.

Correspondence and requests for materials should be addressed to Zhenmeng Peng.

Peer review information Nature Communications thanks Rony Snyders, Bert Weckhuysen and the other, anonymous, reviewer(s) for their contribution to the peer review of this work.

Reprints and permission information is available at http://www.nature.com/reprints

Publisher's note Springer Nature remains neutral with regard to jurisdictional claims in published maps and institutional affiliations.

(c) (i) Open Access This article is licensed under a Creative Commons Attribution 4.0 International License, which permits use, sharing, adaptation, distribution and reproduction in any medium or format, as long as you give appropriate credit to the original author(s) and the source, provide a link to the Creative Commons license, and indicate if changes were made. The images or other third party material in this article are included in the article's Creative Commons license, unless indicated otherwise in a credit line to the material. If material is not included in the article's Creative Commons license and your intended use is not permitted by statutory regulation or exceeds the permitted use, you will need to obtain permission directly from the copyright holder. To view a copy of this license, visit http://creativecommons.org/ licenses/by/4.0/.

(C) The Author(s) 2022 